\title{
Relationship between Hemoglobin A1c Level and Severity of Coronary Artery Disease Among The Hospitalized Patients with Acute Coronary Syndrome.
}

\author{
Syed Dawood Md. Taimur ${ }^{1}$,Sahela Nasrin²,M Maksumul Haq ${ }^{3}$, M A Rashid ${ }^{4}$, Hemanta I Gomes $^{5}$, Farzana Islam ${ }^{6}$
}

\begin{abstract}
:
Background : Diabetes mellitus is one of the important risk factors for coronary artery disease. The hemoglobin A1c is used for evaluating glycemic control in diabetic patients. Here, we conducted the study to evaluate the relationship between HbA1c level and severity of coronary artery disease among the hospitalized patients with ACS.

Materials \& Methods : This cross sectional study was conducted in the department of Cardiology, Ibrahim Cardiac Hospital \& Research Institute, Dhaka, Bangladesh from September 2015 to December 2015. Total of one hundred patients were studied and they were grouped on the basis of their glycaemic status. One hundred patients with acute coronary syndrome were enrolled in this study. Out of them fifty were diabetic $(\mathrm{HbA} 1 \mathrm{c}>6.5 \%)$ and rest of were nondiabetics (HbA1c $<6.5 \%$ ) ( group-A and B).
\end{abstract}

Results: Out of one hundred patients fifty eight were male and fourty two were female. Mean age of patients in group-A was $58.54 \pm 10.22$ years and mean age of patients in group-B was $54.52 \pm 13.69$ years. Mean age of male and female was $57.72 \pm 11.48$ years and 54.0 \pm 13.08 years respectively. Mean $\mathrm{HbA1C}$ of patients in group-A was $11.43 \pm 1.43 \%$ and group-B was
$6.34 \pm 0.915 \% .38 \%$ of group-A and $22 \%$ of group-B had triple vessel disease, $26 \%$ of group-A and $20 \%$ of group$B$ had double vessel disease and $28 \%$ of group-A and $18 \%$ of group-B had single vessel disease, and $8 \%$ of group-A and $40 \%$ of group-B had normal coronary arteries. $48 \%$ patients of age group $46-50$ in group-A had more incidence in coronary artery disease than other age group which was statistically significant ( $p=0.035) .61-75$ years age group in group- $B$ patients had coronary artery disease than other age groups which was statistically not significant $(p=0.084)$. Patients of group-A was significantly relation with coronary artery disease $(p>.001)$ and six times greater coronary artery disease than patients of group-B (OR $=6.15,95 \% \mathrm{Cl}$ for OR =2.074 -18.289).

Conclusions: In this way the importance of appropriate glycaemic control has been emphasized in diabetic patients. This study showed the relation between HbA1c levels and the severity of CAD in patient with type-II diabetes mellitus. Our findings demonstrate that elevated HbA1c level was risk factor for severity of coronary artery disease in ACS patients.

Keywords: HbA1c; Coronary artery disease; Acute coronary syndrome.

1. Assistant Professor \& Associate Consultant, Department of Cardiology, Ibrahim Cardiac Hospital \& Research Institute, Dhaka.

2. Assistant Professor \& Consultant, Department of Cardiology, Ibrahim Cardiac Hospital \& Research Institute, Dhaka.

3. HOD \& Senior Consultant, Ibrahim Cardiac Hospital \& Research Institute, Dhaka

4. CEO \& Senior Consultant, Ibrahim Cardiac Hospital \& Research Institute, Dhaka

5. Assistant Professor \& Associate Consultant, Department of Cardiology, Ibrahim Cardiac Hospital \& Research Institute, Dhaka.

6. Medical Officer \& Resident, Department of Pediatric Hemato-Oncology, Bangabandhu Sheikh Mujib Medical University (BSMMU), Dhaka.

Address of Correspondence: Dr. Syed Dawood Md. Taimur, Assistant Professor \& Associate Consultant, Department of Cardiology, Ibrahim Cardiac Hospital \& Research Institute, 122, Kazi Nazrul Islam Avenue, Dhaka-1000, Bangladesh. Mobile: +8801712801515, Email: sdmtaimur@gmail.com

DOI: http://dx.doi.org/10.3329/bhj.v33i2.39301

Copyright () 2017 Bangladesh Cardiac Society. Published by Bangladesh Cardiac Society. This is an Open Access articles published under the Creative Commons Attribution-NonCommercial 4.0 International License (CC BY-NC). This license permits use, distribution and reproduction in any medium, provided the original work is properly cited and is not used for commercial purposes. 


\section{Introduction}

Chronic hyperglycemia in type 2 diabetes increases the risk of macrovascular events. Though there is continuing uncertainty about its effect on macrovascular outcomes and death ${ }^{1}$, several studies have clearly demonstrated a correlation between type 2 diabetes and acute coronary syndromes (ACS). High prevalence of diabetes and undiagnosed diabetes or pre-diabetic states is seen in patients with stable or unstable coronary artery disease (CAD) ${ }^{2}$.

This link can be attributed to hyperglycemia, insulin resistance, and a clustering of the risk factors for atherosclerosis. Potential mechanisms that could explain the relationship between diabetes mellitus and ACS including decreased insulin sensitivity leading to impaired, increased levels of catecholamines leading to increased myocardial damage and infarct size, hyperglycemia-induced osmotic diuresis and volume depletion, enhanced platelet activation, and inflammatory-immune reactions with increased markers of inflammation. Fatty acids-mediated inhibition of glucose oxidation leads to myocardial cell death, injury of cardiomyocyte plasma membrane, calcium overload, and arrhythmias[3]. Several studies have shown prognostic role of hyperglycemia and diabetes in patients withACS. Hyperglycemia at admission for ACS is associated with less favorable outcome ${ }^{4-7}$.

Though acute hyperglycemia may be due to the preexisting diabetes mellitus, it may also occur as a part of stress response to the disease state. Hemoglobin $\mathrm{A} 1 \mathrm{c}(\mathrm{HbA} 1 \mathrm{c})$ is less influenced by acute stress. Therefore, HbA1c levels may provide insight into the relation between chronic glucose control and patient outcomes. Thus $\mathrm{HbA} 1 \mathrm{c}$ level being a stable indicator of unstressed long-term glycemic control may be a more useful predictor in ACS. HbA1c level is an indicator of average blood glucose concentrations over the preceding 2-3 months, which is a convenient and well known biomarker in clinical practice. It is now recommended as the preferred method for diagnosis and monitoring glycemic control in diabetes mellitus. Studies evaluating the association of $\mathrm{HbA} 1 \mathrm{c}$ with $\mathrm{ACS}$ have reported discrepant results. Several studies showed higher crude mortality rate in patients with elevated $\mathrm{HbA} 1 \mathrm{c}$ following adjustment for many cardiovascular risk factors ${ }^{8-10}$.

Patients with elevated $\mathrm{HbA} 1 \mathrm{c}$ but without known diabetes likely have diabetes that was neither diagnosed nor treated and other relevant cardiovascular risk factors such as hypertension and dyslipidemia that were also untreated before hospitalization, whereas those with diabetes are more likely to be treated with insulin and control the established risk factors ${ }^{12}$. Thus, the prognostic value of $\mathrm{HbA} 1 \mathrm{c}$ level in patients with coronary atherosclerotic disease has not been well characterized and remains controversial. This study was an attempt to know the association between $\mathrm{HbA} 1 \mathrm{c}$ and severity of coronary disease in ACS patients.

\section{Materials and Methods:}

This cross sectional study was done in the department of cardiology, Ibrahim Cardiac Hospital \& Research Institute, Dhaka, Bangladesh from September,2015 to December, 2015. A total of 100 cases admitted in CCU with complaints of typical chest pain and diagnosed as ACS and divided into diabetic $(\mathrm{HbA} 1 \mathrm{c}>6.5 \%)$ and nondiabetic group $(\mathrm{HbA} 1 \mathrm{c}<6.5 \%) \quad$ (group-A and group-B). Patients belonging to age group of 28-85 years, with diagnosis of diabetes mellitus as per American Diabetes Association (ADA) criteria on treatment were selected. Patients with multi-organ failure, congenital or rheumatic heart disease or recent surgery were excluded from the study. Acute coronary syndrome encompasses a) ST-Segment Elevation Myocardial Infarction (STEMI), a condition for which immediate reperfusion therapy should be considered, b) Non-ST-Segment Elevation Myocardial Infarction (NSTEMI) and c) Unstable angina ${ }^{19}$.

After screening, details of patients with regard to symptoms, duration of diabetes mellitus, medical history, and history of smoking were collected. All patients underwent thorough physical examination and the biochemical investigation. They included $\mathrm{HbA} 1 \mathrm{c}$, serum troponin-I, creatinine kinase-MB (CK$M B$ ), electrocardiogram (ECG), and echocardiography. Symptoms of ACS included chest pain, shortness of breath, nausea, vomiting, palpitations, sweating, and anxiety. ACS was established on at least two of the following characteristic symptoms, electrocardiographic changes, typical rise and fall in biochemical parameter like troponin-I was measured ${ }^{11}$. Statistical analysis: Mean \pm standard deviation was reported for continuous variables, and percentages (number) were reported for categorical variables. Continuous variables were compared using unpaired Student's $t$-test, and categorical variables were compared using Chi-square tests. Odds ratios (ORs) and 95\% confidence intervals (Cls) were calculated for each independent variable. All comparisons were two-tailed and $P<0.05$ was considered statistically significant. The entire analysis was performed with Statistical Package for the Social Sciences (SPSS) version 19.0.

\section{Results:}

Out of one hundred patients 58 were male (in group-A had 26 and group-B had 32 ) and 42 were female(24 were in group-A and 18 were in group-B).Mean age of patients in group-A was $58.54 \pm 10.22$ years and group-B was $54.52 \pm 13.69$ years. Mean male age was $57.72 \pm 11.48$ years and mean female age was $54.0 \pm 13.08$ years (Table- 1 ). Group-A patients mean $\mathrm{HbA} 1 \mathrm{C}$ was $11.43 \pm 1.43 \%$ and group-B patients mean $\mathrm{HbA} 1 \mathrm{C}$ was $6.34 \pm 0.915 \%$. 
Table-I

Age distribution between the groups

\begin{tabular}{lccccc}
\hline Age group (years) & \multicolumn{2}{c}{ Group $A(n=50)$} & & \multicolumn{2}{c}{ Group B $(n=50)$} \\
\cline { 2 - 3 } \cline { 5 - 6 } & $n$ & $\%$ & & $n$ & $\%$ \\
\hline $28-45$ & 5 & 10 & 16 & 32 \\
$46-60$ & 26 & 52 & 17 & 34 \\
$61-75$ & 16 & 32 & 15 & 30 \\
$76-85$ & 3 & 6 & 2 & 4 \\
Mean \pm SD & $58.54 \pm 10.22$ & & $54.52 \pm 13.69$ \\
(Years) & \multicolumn{3}{l}{} \\
\hline
\end{tabular}

Eighty percent patients of group-A and eighty six percent patients of group-B had hypertension which was statistically not significant $(p=0.616) .86 \%$ patients of group-A and $52 \%$ patients of group-B had dyslipidaemia which was statistically significant $(p=.001) .38 \%$ patients of group-A and $64 \%$ patients of group-B were smoker which was not statistically significant $(p=0.148)$. Positive family history for IHD was statistically significant $(p=0.001)$ in both group (Table-2).

Table-II

Distribution of risk factors between the groups $(n=100)$

\begin{tabular}{|c|c|c|c|c|c|}
\hline \multirow[t]{2}{*}{ Risk factor } & \multicolumn{2}{|c|}{$\begin{array}{c}\text { Group A } \\
(n=50)\end{array}$} & \multicolumn{2}{|c|}{$\begin{array}{c}\text { Group B } \\
(n=50)\end{array}$} & \multirow[t]{2}{*}{$p$-value* } \\
\hline & $\mathrm{n}$ & $\%$ & $\mathrm{~N}$ & $\%$ & \\
\hline \multicolumn{6}{|l|}{ Smoking Habit } \\
\hline Smoker or Ex-smoker & 19 & 38 & 17 & 34 & \multirow[t]{2}{*}{$.148^{\mathrm{NS}}$} \\
\hline $\begin{array}{l}\text { Non-smoker } \\
\text { Hypertension }\end{array}$ & 31 & 62 & 33 & 66 & \\
\hline Yes & 40 & 80 & 43 & 86 & \multirow[t]{2}{*}{$.616^{N S}$} \\
\hline No & 10 & 20 & 7 & 14 & \\
\hline \multicolumn{6}{|l|}{ Dyslipidaemia } \\
\hline Yes & 43 & 86 & 26 & 52 & \multirow[t]{3}{*}{$.001^{\mathrm{S}}$} \\
\hline No & 7 & 14 & 24 & 48 & \\
\hline \multicolumn{5}{|l|}{ Family H/O IHD } & \\
\hline Yes & 29 & 58 & 23 & 46 & $.001^{\mathrm{S}}$ \\
\hline No & 21 & 42 & 50 & 78.1 & \\
\hline
\end{tabular}

NS $=$ Not Significant,$S=$ Significant

Out of one hundred patients, BMI of 53 patients were within 25-29.9. Ten patients BMI range was 30-34.9 and thirty seven patients BMI range was 18.4-24.9.(Fig-1)

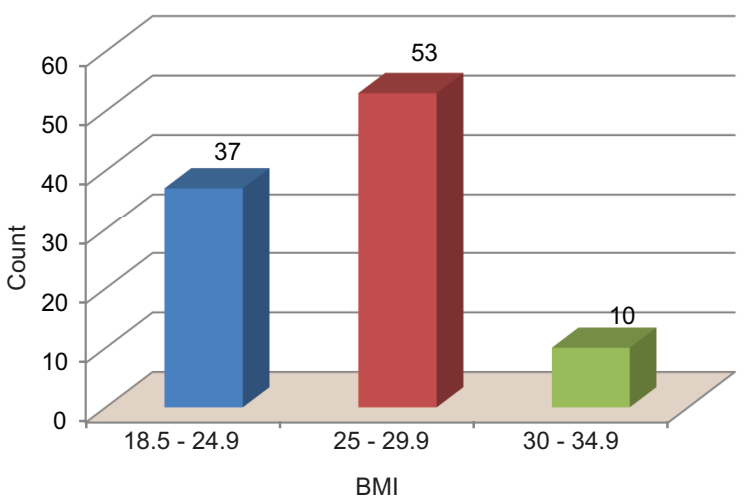

Fig-1: Different BMI range in all age group of patients.

Coronary angiogram was done which revealed thirty percent patients had triple vessel disease, twenty three patients had double vessel disease and twenty one patients had single vessel disease, and rest (24 patients) of had normal coronary arteries. $38 \%$ of group-A and $22 \%$ of group-B had triple vessel disease, $26 \%$ of group-A and $20 \%$ of group-B had double vessel disease and $28 \%$ of group-A and $18 \%$ of group$B$ had single vessel disease, and $8 \%$ of group-A and $40 \%$ of group-B had normal coronary arteries.( Table:-3).

Table-III

Distribution of coronary artery disease between two groups

\begin{tabular}{lccc}
\hline CAD & Group-A & Group-B & p-value \\
\hline SVD & $14(28 \%)$ & $9(18 \%)$ & \\
DVD & $13(26 \%)$ & $10(20 \%)$ & 0.776 NS \\
TVD & $19(38 \%)$ & $11(22 \%)$ & \\
Normal & $4(8 \%)$ & $20(40 \%)$ & \\
\hline
\end{tabular}

NS=Not significant

Within group-A, 46-60 years age group had more incidence $(48 \%)$ in coronary artery disease than other age group which was statistically significant ( $p=0.035)$. In group$B, 61-75$ years age group had more frequency(26\%) of coronary artery disease than other age groups which was statistically not significant $(p=0.084)$. (Table-4)

Table-IV

Frequency of coronary artery disease in different age group

\begin{tabular}{|c|c|c|c|c|c|c|}
\hline \multirow{2}{*}{$\begin{array}{l}\text { Age Group } \\
\text { Years }\end{array}$} & \multicolumn{2}{|c|}{ Group-A } & \multirow[t]{2}{*}{ p-value } & \multicolumn{2}{|c|}{ Group-B } & \multirow[t]{2}{*}{ p-value } \\
\hline & Frequency & Percentage (\%) & & Frequency & Percentage (\%) & \\
\hline $28-45$ & 3 & 6 & & 7 & 14 & \\
\hline $46-60$ & 24 & 48 & $0.035^{\mathrm{s}}$ & 9 & 18 & $0.084^{\mathrm{NS}}$ \\
\hline $61-75$ & 16 & 32 & & 13 & 26 & \\
\hline $76-85$ & 3 & 6 & & 1 & 2 & \\
\hline
\end{tabular}

NS = Not Significant, $S=$ Significant 
Out of 100 patients, 46 patients of group $A$ and 29 patients of group $B$ had coronary artery disease which is statistically significant $(p<0.05)$. Adjusted OR for association of elevated $\mathrm{HbA1c}$ with acute coronary syndrome when analyzed by regression analysis adjusting for confounders like dyslipidemia, family history of ischemic heart disease. HbA1c showed strong relation with adjusted odds ratio $=6.159(\mathrm{Cl}$ : 2.074-18.289). (Table-V)

Table-V

Correlation between $\mathrm{HbA} 1 \mathrm{C}$ and coronary artery disease

\begin{tabular}{|c|c|c|c|c|c|c|}
\hline & \multicolumn{2}{|c|}{$\begin{array}{c}\text { Coronary artery } \\
\text { disease }\end{array}$} & \multirow[t]{2}{*}{ Total Pt } & \multirow[t]{2}{*}{ OR } & \multirow[t]{2}{*}{$95 \% \mathrm{Cl}$} & \multirow[t]{2}{*}{ Pvalue } \\
\hline & Yes & No & & & & \\
\hline Group A & 46 & 4 & 50 & & & \\
\hline Group B & 29 & 21 & 50 & 6.159 & $\begin{array}{l}2.074- \\
18.289\end{array}$ & $0.00^{s}$ \\
\hline
\end{tabular}

S = Significant

\section{Discussion:}

Many studies have clearly demonstrated the strong association of $\mathrm{HbA} 1 \mathrm{c}$ with macrovascular complications in type II diabetes mellitus. There are few studies in the western literature reporting the association of $\mathrm{HbA} 1 \mathrm{c}$ with macrovascular complications like ACS. The present study was done to know the relationship of $\mathrm{HbA} 1 \mathrm{c}$ level with ACS in our population. The cohort study done by Selvin and colleagues [14] on 7435 patients with type 2 diabetes mellitus has shown that $1 \%$ increase $\mathrm{HbA} 1 \mathrm{c}$ was associated with $18 \%$ increase in the risk of coronary heart disease.

In our study, difference between mean $\mathrm{HbA} 1 \mathrm{c}$ among groupA and group-B was statistically significant. Subgroup analysis based on status of dyslipidaemia and positive family history of IHD also showed similar results. The prospective population study done by Khaw KT.et al., [15] on 10232 subjects has shown that after adjustment for systolic blood pressure, cholesterol level, body mass index, waist-hip ratio, smoking, and previous myocardial infarction or stroke, there was a $21 \%$ increase in cardiovascular events for every $1 \%$ increase in $\mathrm{HbA} 1 \mathrm{c}$ level above $5 \%$.

According to age patients were categorized into different age group, group-A \& B, within 46-60 years age group of group-A $(P=0.035)$ had higher frequency of coronary artery disease ,on the other hand 61-75 age group of group$B(p=0.084)$ had also higher frequency of coronary artery disease which was statistically not significant on the other hand higher incidence of coronary artery disease found in Razu HN et al.[11] and Mehmet FO et al.[13]. There are several biologically possible mechanisms that might account for the finding that chronic hyperglycemia is associated with
ACS. Hyperglycemic periods play a major role in the activation of oxidative stress and overproduction of mitochondrial superoxide, which trigger various metabolic pathways of glucose-mediated vascular damage[16,17]. Glucose can react with various proteins to form advanced glycation end products, which may contribute to long term complications in diabetes, plaque formation, and atherosclerosis[18]. These effects are gradual and likely to be cumulative, occurring during decades of exposure to chronically elevated blood glucose levels. Elevated $\mathrm{HbA} 1 \mathrm{c}$ level is likely the result of long-term insulin resistance.

Metabolic disturbances associated with insulin resistance including hyperglycemia, dyslipidemia, hypercoagulability, and inflammation might play a major role in the adverse impact of elevated $\mathrm{HbA1c}$ on cardiovascular system. Limitations of the present study was small group of patients so that we did not collect the long term follow up details and mortality associated with ACS in relation to $\mathrm{HbA} 1 \mathrm{c}$ level. The number of patients in each group was also small to calculate cardiovascular risk with increase in percentage of $\mathrm{HbA1c}$.

\section{Conclusion:}

$\mathrm{HbA} 1 \mathrm{c}$ level was strongly related with risk of coronary artery disease specially those patients who were diagnosed as ACS. Occurrence of ACS was significantly more in patients with diabetic with poorly controlled blood sugar level when compared with nondiabetic patients. Our finding supports the notion that diabetic patients with higher $\mathrm{HbA} 1 \mathrm{c}$ level should be closely followed due to their higher risks of cardiovascular outcomes. glycemic control may help to reduce cardiovascular events in type 2 diabetic patients.

\section{References:}

1. Zhang Y, Hu G, Yuan Z, Chen L. Glycosylated hemoglobin in relationship to cardiovascular outcomes and death in patients with type 2 diabetes: Asystematic review and metaanalysis. PLoS One 2012;7:e42551.

2. De Caterina R, Madonna R, Sourij H, Wascher T. Glycaemic control in acute coronary syndromes:prognostic value and therapeutic options. Eur Heart J 2010;31:1557-64.

3. DeFronzo RA. Pathogenesis of type 2 diabetes mellitus. Med Clin North Am 2004;88:787-835.

4. Capes SE, Hunt D, Malmberg K, Gerstein HC. Stress hyperglycaemia and increased risk of death after myocardial infarction in patients with and without diabetes: A systematic overview. Lancet 2000;355:773-8. 
5. Bolk J, van der Ploeg T, Cornel JH, Arnold AE, Sepers J, Umans VA. Impaired glucose metabolism predicts mortality after a myocardial infarction. Int J Cardiol 2001;79:207-14.

6. Wahab NN, Cowden EA, Pearce NJ, Gardner MJ, Merry $\mathrm{H}$, Cox JL, ICONS Investigators. Is blood glucose an independent predictor of mortality in acute myocardial infarction in the thrombolytic era? J Am Coll Cardiol 2002;40:1748-54.

7. Foo K, Cooper J, Deaner A, Knight C, Suliman A, Ranjadayalan $\mathrm{K}$, et al. A single serum glucose measurement predicts adverse outcomes across the whole range of acute coronary syndromes. Heart 2003;89:512-6.

8. Cakmak M, Cakmak N, Cetemen S, Tanriverdi H, Enc $\mathrm{Y}$, Teskin $\mathrm{O}$, et al. The value of admission glycosylated hemoglobin level in patients with acute myocardial infarction. Can J Cardiol 2008;24:375-8.

9. Hadjadj S, Coisne D, Mauco G, Ragot S, Duengler F, Sosner P, et al. Prognostic value of admission plasma glucose and $\mathrm{HbA}$ in acute myocardial infarction. Diabet Med 2004;21:305-10.

10. Timmer JR, Hoekstra M, Nijsten MW, van der Horst IC, Ottervanger JP, Slingerland RJ, et al. Prognostic value of admission glycosylated hemoglobin and glucose in nondiabetic patients with ST-segmentelevation myocardial infarction treated with percutaneous coronary intervention. Circulation 2011;124:704-11.

11. Raju Hosuru Narayana, Nithyananda Chowta Kallige, Mangalore Venkatraya Prabhu et al. Glycosylated hemoglobin and acute coronary syndrome in type 2 diabetes mellitus. Arch Med Health Sci. Jan-Jun 2015; $3(1): 29-33$
12. Britton $\mathrm{KA}$, Aggarwal $\mathrm{V}$, Chen $\mathrm{AY}$, Alexander $\mathrm{KP}$, Amsterdam E, Fraulo E, et al. No association between hemoglobin a1c and in-hospital mortality in patients with diabetes and acutemyocardial infarction. Am Heart J 2011;161:657-63.

13. Memmet Fatih Ozlu,Suzi Selim Ayhan,Serkan Ozturk et al. Relationship between $\mathrm{HbA} 1 \mathrm{c}$ levels and severity of coronary artery disease in diabetic patients. J Uni Harran Med Faculty,2012:15-19.

14. Selvin E, Marinopoulos S, Berkenblit G, Rami T, Brancati FL, Power NR, et al. Meta-analysis: Glycosylated hemoglobin and cardiovascular disease in diabetes mellitus. Ann Intern Med 2004;141:421-31.

15. Khaw KT, Wareham N, Bingham S, Luben R, Welch A, Day N.Association of hemoglobin A1C with cardiovascular disease and mortality in adults. Ann Intern Med 2004;141:413-20.

16. Brownlee M, Hirsch IB. Glycemic variability: A hemoglobin A1c-independent risk factor for diabetic complications. JAMA 2006;295:1707-8.

17. Monnier L, Mas E, Ginet C, Michel F, Villon L, Cristol JP, et al. Activation of oxidative stress by acute glucose fluctuations compared with sustained chronic hyperglycemia in patients with type 2 diabetes. JAMA 2006;295:1681-7.

18. Sheetz MJ, King GL. Molecular understanding of hyperglycemia's adverse effects for diabetic complications. JAMA 2002;288:2579-88.

19. Anderson, JL, Adams, CD, Antman, EM, Bridges, C R, Califf, RM, Casey, DE, Chavey, WE, Fesmire, F M, Hochman, JS, Levin, T. N. , Lincoff, A. M. , Peterson, ED, Theroux, P, Wenger, NK, Wright, RS, Jneid, H, Ettinger, SM, Ganiats, TG, Philippides, GJ, Jacobs, A K \& 9 others Jun 112013 In : Am Coll Cardiol. 61, 23. 